\title{
A Software Requirement Engineering Framework to Enhance Critical Success Factors for ERP Implementation
}

\author{
Nafisa Osman \\ Sudan University for Science and Technology \\ Khartoum \\ Sudan
}

\author{
Abd-El-Kader Sahraoui \\ LAAS-CNRS, Université de Toulouse, \\ CNRS, UTJJ, Toulouse \\ France
}

\begin{abstract}
Requirement it's most critical success or failure factor for system. Enterprise Resource Planning (ERP) one of famous enterprise system and many studies focus on define CSF of it to reduce failing cases of ERP implementation and negative factors affecting not only on implementing company but also on the ERP vendors.

Many papers have studied the CSF influence in ERP implementation but very little concern about requirement engineering (RE). This research will fill the gap by providing critical review and develop an approach in software system engineering framework by taking account feedback from stakeholders. This original approach is how to deal with ERP failure through a depth relation related to requirement engineering traceability to CSF in a system engineering view (SOS) based on ANSI EIA 632 standard.
\end{abstract}

\section{Keywords}

Enterprise resource planning; critical success factor; requirement engineering; collaboration engineering; standard EIA 632; System Of System.

\section{INTRODUCTION}

Management information system (MIS )reflect the development of technology and all organizations take advantage of it to automate organization process and get competitive advantages and effectiveness in planning and managing of organization activities . Most important feature for business organization its integration between organization units to guarantee consistent and available data to help dissection maker. This feature provide it via Enterprise Resource Planning (ERP) which is define as integrated unified information system automate organization business process such as (human resource ,finance, and manufacturing ...etc )into single database. ERP was first introducing by research and analysis firm Gartner in 1990 and designed to solve fragmentation problem. [1, 2, 3, 4]. We can consider such as System Of Systems (SOS) and our view is intended to such endeavor [4].

With integration feature ERP provide a lot of benefits, some of it listed below: $[5,6]$

1. Improve organization effectiveness and productivity.

2. Enhance the competitiveness of organization in market place.

3. Improve customer, inventory and asset management.

4. Faster and more accurate transaction.

Despite all previous benefits .ERP implementation with high failure rate depend on the statistical failure rate of an ERP implementation project between $60 \%$ and $90 \%$ and $90 \%$ of SAP R3 /ERP project run late. [7]

We have valid statistics of an ERP failure in the past years. According to [8] the average cost of an ERP implementation project over $\$ 6.1$ million.

$58 \%$ of these projects exceeds their planned
budget $65 \%$ schedule overrun

$53 \%$ of implementing organizations achieve less than $50 \%$ of measurable benefits expected from new ERP software. This failure does not affect only on implementing companies just but also affect on ERP vendors because ERP vendors must pay compensation for implementing companies [3].

\subsection{Problem Statement}

In order avoid this failure or try to minimize rate a lot researcher make studies to define critical success factors (CSF) /critical failure factors (CFF) of ERP implementation with deep analysis and categorization.

One of the first articles of ERP failure defines failure reasons as lack of education, business process reengineering (BPR), project management and unrealistic expectation of user [7]. Other studies categorize CSF to operational ,organizational and cultural factors .other classification depends on ERP implementation phases .CSF in pre-implementation phase such as clear objectives and scope ,right product selection ...etc.CSF in implementation phase such as BPR ,management involvement and effective communication .The last phase is post- implementation consists employee motivation ,software reliability and end user satisfaction as CSF.[9]

But unsatisfactory user requirement is mostly due CSF and with increasing rate of ERP implementation requirement satisfaction still problem .one of example of these cases when Cosmetic Co company chose MOVEX software as an ERP package, however, this system was not fully translated to Chinese language and the financial tables were not compatible with the requirements of the Chinese government, which causes a lot of delay in the manufacturing process, and as a result, the service provider had to pay USD 250,000 to Cosmetic Co Company[3].

We come to the point that the essence is how to gather requirements for ERP; this should multiple ways of gathering. These methods that can range from using existing templates as proposed in VOLERE template or requirements elicitation methods that had been an active research field in late 2000.

Depend on statistics expansion of initial project scope cited 
by $50 \%$, which is a reason behind extended duration of ERP projects also, poor fit and lack of functionality represent $5 \%$ of the reason behind budget overage of ERP projects[6].

All previous cases related to requirements issues and most of ERP literatures say little about requirements engineering (RE) [10].This study focused on implementing ERP from RE perspective.

At ERP, requirements meets via select and acquiring suitable ERP software fulfill an organization function and able to customization process for any extra requirements

\section{CRITICAL STUDY ON CSF IN ERP AND PRELIMINARY APPROACH}

\subsection{The Approach}

This research focus on the following question which already defined before the start of the literature review.

1. Identify CSF of ERP implementation

2. Classify identifies CSF according to the requirement engineering view

For this author focus on papers and documents contains the following keywords "Enterprise resource planning implementation" and "critical success factors".

All paper review characterized by

1. clearly related to research questions

2. come from trusted journals and conferences

3. publication year of the paper at 2012 or above

After 15 articles have been reviewed and used as a resource for CSF of ERP implementation[11] [12][13][14].author discovered 46 CSF listed in the table [1] after careful analysis of CSF mentioned at the literature review via eliminate similar CSF or merging it in one CSF. [15][16][17][18]

Table 1. CSF for ERP implementation

\begin{tabular}{|l|l|}
\hline$\#$ & CSF \\
\hline 1. & Good project scope management \\
\hline 2. & Management expectations \\
\hline 3. & Project management \\
\hline 4. & Steering committee \\
\hline 5. & Legacy system \\
\hline 6. & Culture change / political issue and regulation \\
\hline 7. & Formalized project /plan schedule \\
\hline 8. & Business process reengineering \\
\hline 9. & Experience project manager leadership \\
\hline 10. & Project champion role \\
\hline 11. & Trust between partners \\
\hline 12. & Interdepartmental cooperation and communication \\
\hline 13. & $\begin{array}{l}\text { Project team composition /team skill and team } \\
\text { competence }\end{array}$ \\
\hline 14. & Empowered decision maker \\
\hline 15. & $\begin{array}{l}\text { Management involvement } \\
\text { commitment }\end{array}$ \\
\hline 16. & Monitor and evaluation progress and performance \\
\hline 17. & Appropriate use and managing consultant \\
\hline 18. & Vendor tools \\
\hline 19. & Software customization \\
\hline 20. & Software configuration \\
\hline 21. & Appropriate technology and good IT infrastructure \\
\hline 22. & Reduce trouble shooting and project risk \\
\hline 23. & Training software \\
\hline & \\
\hline
\end{tabular}

\begin{tabular}{|l|l|}
\hline 24. & Education on new business process \\
\hline 25. & Vendor support \\
\hline 26. & Data analysis and conversation \\
\hline 27. & Formal ERP implementation methodology \\
\hline 28. & $\begin{array}{l}\text { Careful define information and system } \\
\text { requirements }\end{array}$ \\
\hline 29. & Adequate ERP software selection \\
\hline 30. & Clear goal and objectives \\
\hline 31. & Careful change management \\
\hline 32. & End user involvement \\
\hline 33. & Organization fit ERP \\
\hline 34. & Motivational factor for ERP implementation \\
\hline 35. & Company wide support \\
\hline 36. & Business plan long term vision \\
\hline 37. & Vendor /customer partnership \\
\hline 38. & Integration business plan with ERP planning \\
\hline 39. & Ease of system use and user acceptance \\
\hline 40. & Data and information quality \\
\hline 41. & Focus on user requirement \\
\hline 42. & Rewards and recognition \\
\hline 43. & Standardized implementation sequence \\
\hline 44. & End user satisfaction \\
\hline 45. & Software reliability \\
\hline 46. & Adequate testing of system \\
\hline
\end{tabular}

\subsection{Requirement engineering view for CSF}

Requirement engineering required for every software development and implementation even little literature about RE in ERP implantation projects, but some of CSF related to it. Table [2] shows these CSF.

Table 2. CSF for ERP implementation related to RE

\begin{tabular}{|r|c|}
\hline \multicolumn{1}{|c|}{$\#$} & CSF \\
\hline 1. & Good project scope management \\
\hline 2. & Legacy system \\
\hline 3. & Culture change / political issue and regulation \\
\hline 4. & Business process reengineering \\
\hline 5. & Software customization \\
\hline 6. & $\begin{array}{c}\text { Careful define information and system } \\
\text { requirements }\end{array}$ \\
\hline 7. & Adequate ERP software selection \\
\hline 8. & Clear goal and objectives \\
\hline 9. & Careful change management \\
\hline 10. & End user involvement \\
\hline 11. & Management involvement support and \\
& commitment \\
\hline 12. & Appropriate use and managing consultant \\
\hline 13. & Focus on user requirement \\
\hline 14. & End user satisfaction \\
\hline 15. & Adequate testing of system \\
\hline 16. & Vendor support \\
\hline
\end{tabular}

\section{THE METHODOLOGICAL APPROACH}

\subsection{Requirements to CSF traceability}

Requirement engineering is main part and initial activity of software engineering concern about defining stakeholder requirements and relationships between different requirements. The main reason of project failure is poor requirements engineering [19]. RE define as "branch of software engineering concern with the real world goals for, functions of, and constrains on software system it also 
concerns with the relationship of these factors to precise specification of software behavior, and to their evolution overtime and across software families"[20]

RE takes the following input: [21] [22]
1. Existence system information
2. Stakeholder needs
3. Organizational structure
4. Regulations
5. Domain information

There is a need for traceability between low level requirements, high level requirements and stakeholder at all levels, managers to end users. This can best illustrated in "fig $1 "[21]$

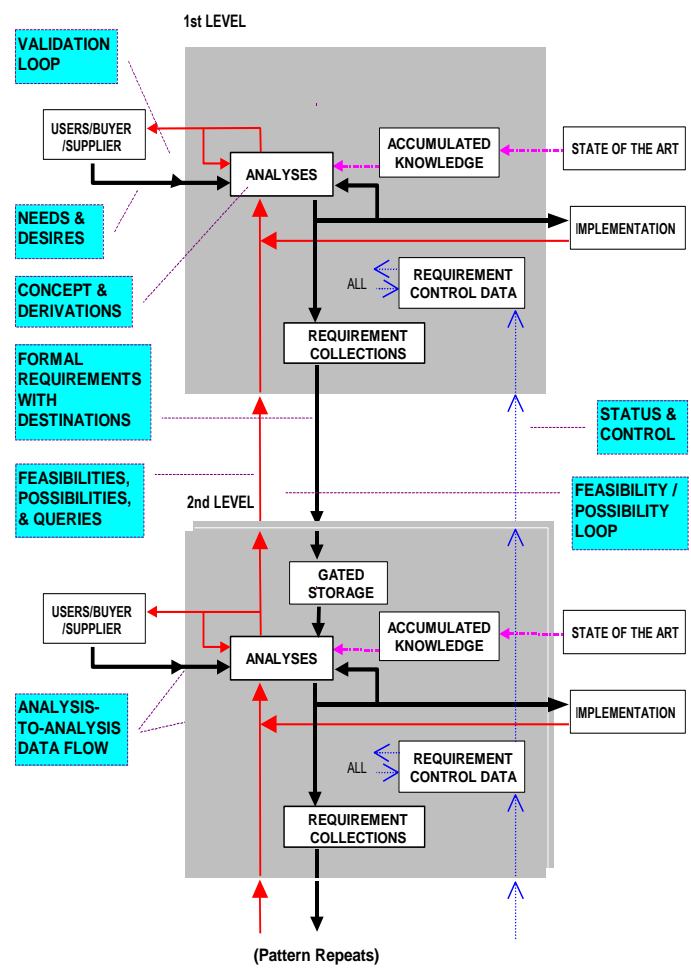

Figure 1. Requirements and levels of abstraction

These RE input overlap with CSF of ERP as following in table [3].

Table 3. CSF for ERP implementation overlaps with RE input

\begin{tabular}{|c|c|}
\hline RE input & CSF \\
\hline $\begin{array}{c}\text { Existence system } \\
\text { information }\end{array}$ & $\begin{array}{c}\text { Careful define } \\
\text { information and system } \\
\text { requirement/legacy } \\
\text { system }\end{array}$ \\
\hline Stakeholder needs & $\begin{array}{c}\text { Focus on user } \\
\text { requirements /clear } \\
\text { goals and objectives }\end{array}$ \\
\hline $\begin{array}{c}\text { Organizational } \\
\text { structure }\end{array}$ & $\begin{array}{c}\text { Culture change } \\
\text { Regulations } \\
\text { /political issues and } \\
\text { regulations }\end{array}$ \\
\hline Domain information & - \\
\hline
\end{tabular}

Stakeholders must be identified during RE because they are key term for collecting requirements and RE concern about stakeholder expectations [23]. One ERP CSF is managing expectations, but at ERP there are different groups of stakeholders defined at different CSF such as End user involvement, top management involvement and appropriate use and managing consultant.

Stakeholders group in ERP are actors [Error! Bookmark not defined.]:
1. End user
2. Top management
3. IT departments
4. Project team
5. Vendor
6. ERP consultant
7. Employees from different departments
8. Business process expert

Good project scope management (CSF1) is one of requirements basic to bound problem /solution scope [24]. All requirements defined from different group of stakeholders within scope must be embedded when select ERP (CSF7), customized (CSF5) and testing (CSF15) to get end user satisfaction (CSF14).

\section{PROPOSED FRAMEWORK}

Depend on previous part we need framework solve differentiation of stakeholders view for that we propose merging RE process and creativity, collaboration engineering process to guarantee all stakeholders involvement in novel way that for nature of RE is an interaction of groups of stakeholders working together to find valuable solution for complex system.

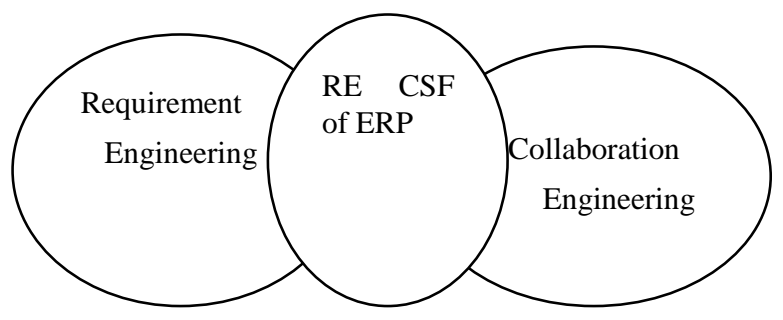

Figure 2. Proposed Framework

Our framework begins with preparation activity to identify and categorize all relevant stakeholders then specify every stakeholder must be involved at RE process. This activity also concern to define suitable tools for RE activities

Even project scope related to the requirement but, at a preparation activity we need to guarantee well define project scope and boundaries embedded company goal and objectives via project management, top management and steering committee then shared scope between other stakeholders to keep shared knowledge .

After the preparation activity, frame work start implements different RE activity shown in "fig 3"such as Elicitation, analysis and management at collaborative way depend on predefined tool and stakeholders group. 


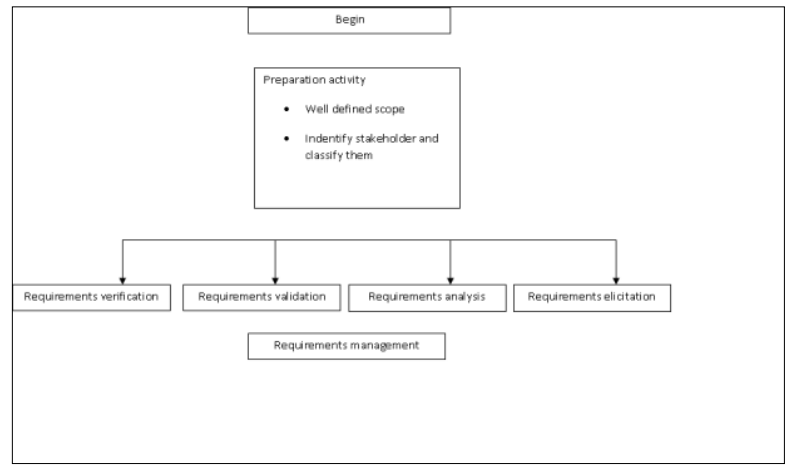

Figure 3. Framework activities

Modeling collaborative actors

We classify actors to key stakeholders define requirements include the following actors :
A. End user
B. IT departments
C. Employees from different departments

Other group give help to define requirements include:

1. ERP consultant

2. Business process expert

For project management and requirements engineering activities we have project team actors .finally for decision making we have last group include:

$$
\begin{aligned}
& \text { 1. Top management } \\
& \text { 2. Vendor }
\end{aligned}
$$

All stakeholders shown in "fig 4 ".

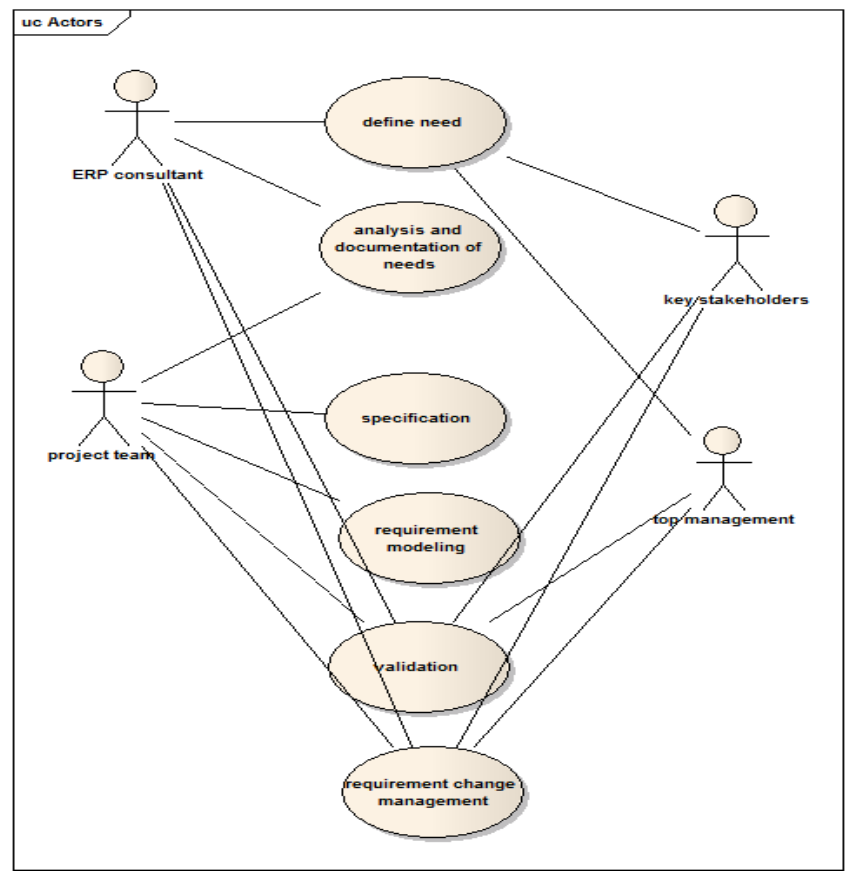

Figure 4. Modeling collaborative actors

From previous figure the creative collaboration arises between different stakeholders at different RE activities that help to include all stakeholder requirements and fulfill the CSF and get user satisfaction.

\subsection{Requirement change}

The requirements change is a common issue not only in legacy systems but all systems

\subsection{Requirements change in ERP versus requirements in standards}

As mentioned in previous part, the customers have the right to make requirements changes and often at later stage of the process. This has a positive effect for the customers but we have drawbacks

- Delay in delivery

- Safety issues as the customers do not see the scope of the requested change.

Most changes come customers and in site when available ERP has to be adapted to customers.

From that respect, Validation and verification issues must be observed. We are oriented more such systems engineering standards ANSIS EIA-632, Where the validation process describe as follow:

EIA 632: include eight requirements for $\mathrm{V} \& \mathrm{~V}$ and one end pro-duct Validation, we used such standard in our study

- Val1 (Req 25): Requirements statements validation

- Val2 (Req 26): Acquirer requirements validation

- $\quad$ Val3 (Req 27): Other stakeholder requirement validation

- $\quad$ Val4 (Req 28): System technical requirements validation

- Val5 (Req 29): Logical solution representations validation

- Ver1 (Req 30): Design solution verification

- $\quad$ Ver2 (Req 31): End product verification

The systems development is based on unified process. These processes make abstraction of the systems nature.

We can see that requirement statements by end users are important and explicitly mentioned in the standard.

\subsection{Proposed process and integration to the methodology}

We know that any requirement change will concern and trigger all four models. In our first approach we will be concerned the change, traceability and development models. However, some principles will guide towards the deepening of the approach as future work will focus mainly on refining the approach:

- Any change request either at any step of development model suppose the availability of a traceability model.

- A change request for an operation module will necessarily require tracing back the original requirement

- Make distinction between functional and non function requirements

- Identify security/safety requirements.

- Create link between associated function and safety requirement.

\subsection{Deploying the 8 processes}

Considering the specific design processes as presented in "fig 5" 


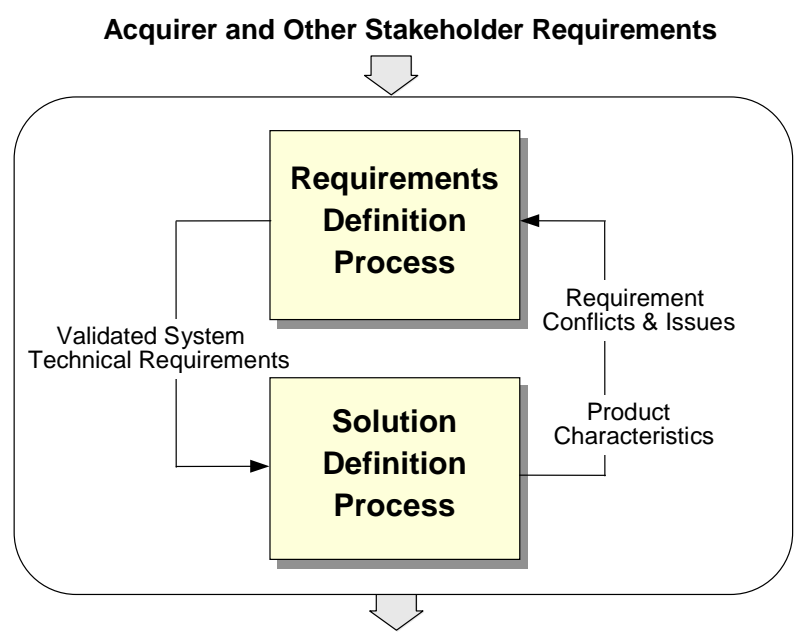

ERP change requirement and solution definitions

Figure 5. Integration of process

We were concerned by these two processes mainly as our initial work was on managing requirements change while the system is on development either at the requirement or design process levels even though both processes were active.

The data flow on data bus in EIA 632 enable concurrent processes for data exchange ; the standard does not impose any standard for exchange ; however as we have software support tools for most processes.

\subsection{Formal Basis: A Need for SCM Integration}

As ERP becomes a tool that has implication in all aspects of product development and management; it is a possible that there is a need for a Formal framework as to avoid emergent properties that can harm the systems globally. ERP plays an essential role in supply chain. In that context, it is planned to initiate a simulation approach first to get SCM integrated in an ERP; the formal basis will be the used of advances formal tools for simulation. Colored Petri nets being the model and $\mathrm{CPN}$ will be the software tools

\section{CONCLUSION}

The goal of this paper to fill the gap of study of CSF of ERP implementation from RE process perspective. For this purpose well analysis for literature conclude $16 \mathrm{CSF}$ related to RE process and make impact on ERP implementation project life cycle for that the paper propose simple framework help to manage $\mathrm{RE}$ process at ERP implementation projects .

We showed that the essential, was to focus first on requirements issues. The requirements issue consisted in requirement traceability to success factor and also at the requirements volatility/change.

We are on the process of implementing such process for our customers of Almedtech Inc.

\section{ACKNOWLEDGMENT}

We grateful to all people who contribute directly to such work; funding from Almedtech (www.almedtech.com), their customer companies for the feedback, academic support from Sudan university for science and technology University and affiliated faculty from European University mainly from Germany and France.

\section{REFERENCES}

[1] Frimpon, Michael F. "A re-structuring of the enterprise resource planning implementation process." International Journal of Business and Social Science 2.24 (2011).

[2] Ijaz, Aamir, et al. "A Qualitative Study of the Critical Success Factors of ERP System-A Case Study Approach." International Conference on Industrial Engineering and Operations Management, Indonesia. 2014.

[3] Tarhini, Ali, Hussain Ammar, and Takwa Tarhini. "Analysis of the critical success factors for enterprise resource planning implementation from stakeholders' perspective: A systematic review." International Business Research 8.4 (2015): 25.

[4] Osman, N. "Requirement in systems of systems."International conformation in Information technology, Istanbul, April 2015.

[5] Zeng, Yajun, Yujie Lu, and Miroslaw Skibniewski. "Enterprise resource planning systems for project-based firms: benefits, costs \& implementation challenges." Journal for the Advancement of Performance Information \& Value 4.1 (2012).

[6] Manufacturing ERP report. A Panorama Consulting Solutions Research Report,2015 .

[7] Ravasan, Ahad Zare, and Taha Mansouri. "A FCMbased dynamic modeling of ERP implementation critical failure factors." International Journal of Enterprise Information Systems (IJEIS) 10.1 (2014): 3252

[8] ERP REPORT. A Panorama Consulting Solutions Research Report. 2015

[9] Ahmad, M. Munir, and Ruben Pinedo Cuenca. "Critical success factors for ERP implementation in SMEs." Robotics and Computer-Integrated Manufacturing 29.3 (2013): 104-111.

[10] Daneva, Maya. "Understanding success and failure profiles of ERP requirements Engineering: an Empirical Study." Software Engineering and Advanced Applications, 2007. 33rd EUROMICRO Conference on. IEEE, 2007.

[11] Khattak, R.A., Khattak, M.M.S., Khattak, M.A.O., Irfan, M., \& Yuanguan, S. (2012). "Examining critical success factors affecting ERP implementations in enterprises of Pakistan.” Interdisciplinary Journal of Contemporary Research in Business, vol. 3, no. 10, February 2012

[12] Saravanan, R., and C. Sundar. "Derivation and validation of a conceptual model forERP implementation success factors , an Indian context." Journal of Theoretical and Applied Information Technology 78.1 (2015): 132.

[13] Abu-Shanab, Emad, Rasha Abu-Shehab, and Mousa Khairallah. "Critical success factors for ERP implementation: The case of Jordan." The International Arab Journal of e-Technology 4.1 (2015): 1-7.

[14] Bansal, Veena. "Identifying critical success factors for ERP in SMEs through a case study." International Journal of Future Computer and Communication 2.5 (2013): 471.

[15] Ziemba, Ewa, and Iwona Oblak. "Critical success 
factors for ERP systems implementation in public administration." Interdisciplinary Journal of Information, Knowledge, and Management 8 (2013): 119.

[16] Amini, Mahyar, and Nazli Sadat Safavi. "Review paper: critical success factors for ERP implementation." International Journal of Information Technology \& Information Systems 5.15 (2013): 1-23.

[17] AlSudairi, Mohammed AT. "Analysis and exploration of critical success factors of ERP implementation: a brief review." International Journal of Computer Applications 69.8 (2013).

[18] Rouhani, Saeed, Amir Ashrafi, and Samira Afshari. "Segmenting critical success factors for ERP implementation using an integrated fuzzy AHP and fuzzy DEMATEL approach." World Applied Sciences Journal 22.8 (2013): 1066-1079.

[19] Hassan, Shoaib, et al. "Software Reverse Engineering to Requirement Engineering for Evolution of Legacy
System." IT Convergence and Security (ICITCS), 2015 5th International Conference on. IEEE, 2015.

[20] Laplante, Phillip A. Requirements engineering for software and systems. CRC Press, 2013.

[21] A.E.K Sahraoui, D. Jones. "Requirements traceability model."Int'c conf Systems engineering, Arizona, 2001

[22] Ur Rehman, Tousif, Muhammad Naeem Ahmed Khan, and Naveed Riaz. "Analysis of Requirement Engineering Processes, Tools/Techniques and Methodologies." (2013).

[23] Majumdar, Shariful Islam, Md Saidur Rahman, and Md Mijanur Rahman. "Stakeholder Prioritization in Requirement Engineering Process: A Case Study on School Management System." Computer Science and Engineering 4.1 (2014): 17-27.

[24] I. hooks. Managing requirements for system of system. The Journal of Defense Software Engineering, VOL. 17, NO.8 pp.4. August 2004. 